\title{
Acidic preparations of lysed platelets upregulate proliferative pathways in osteoblast- like cells as demonstrated by genome-wide microarray analysis
}

\author{
Ola Wahlström, Cecilia Linder, Anna Ansell, Anders Kalén, \\ Mats Söderström and Per Magnusson
}

\section{Linköping University Post Print}

N.B.: When citing this work, cite the original article.

Original Publication:

Ola Wahlström, Cecilia Linder, Anna Ansell, Anders Kalén, Mats Söderström and Per Magnusson, Acidic preparations of lysed platelets upregulate proliferative pathways in osteoblast-like cells as demonstrated by genome-wide microarray analysis, 2011, Platelets, (22), 6, 452-460.

http://dx.doi.org/10.3109/09537104.2011.565432

Copyright: Informa Healthcare http://informahealthcare.com/

Postprint available at: Linköping University Electronic Press http://urn.kb.se/resolve?urn=urn:nbn:se:liu:diva-70115 
January 31, 2011

Journal: Platelets

Running title: Microarray analysis of osteoblast-like cells

\title{
Acidic preparations of lysed platelets up-regulate proliferative pathways in osteoblast-like cells as demonstrated by genome-wide microarray analysis
}

\author{
Ola Wahlström ${ }^{1}$, Cecilia Halling Linder ${ }^{2,3}$, Anna Ansell ${ }^{4}$, Anders Kalén ${ }^{1}$, \\ Mats Söderström ${ }^{5}$, and Per Magnusson ${ }^{2,3}$
}

${ }^{1}$ Division of Orthopaedics, Department of Clinical and Experimental Medicine, Faculty of Health Sciences at Linköping University, Linköping, Sweden

${ }^{2}$ Bone and Mineral Metabolic Unit, Division of Clinical Chemistry, Department of Clinical and Experimental Medicine, Faculty of Health Sciences at Linköping University, Linköping, Sweden

${ }^{3}$ Division of Clinical Chemistry, County Council of Östergötland, Linköping, Sweden

${ }^{4}$ Division of Otorhinolaryngology, Department of Clinical and Experimental Medicine, Faculty of Health Sciences at Linköping University, Linköping, Sweden

${ }^{5}$ Division of Cell Biology, Department of Clinical and Experimental Medicine, Faculty of Health Sciences at Linköping University, Linköping, Sweden

Corresponding author:

Per Magnusson, Ph.D., Associate Professor

Bone and Mineral Metabolic Unit

Division of Clinical Chemistry

Department of Clinical and Experimental Medicine

Faculty of Health Sciences at Linköping University

SE-581 85 Linköping

Sweden

Tel: +46-10-103 3997

Fax: +46-10-103 3240

E-mail: per.magnusson@lio.se

Keywords: cell proliferation, gene expression, hypoxia, platelets, TGFBR pathway 


\begin{abstract}
Platelets contain numerous growth factors essential for wound and fracture healing. We investigated the gene expression in human osteoblast-like cells stimulated with lysed platelets prepared in acidic, neutral or alkaline buffers. Lysed platelets prepared in buffers at $\mathrm{pH}$ 5.4, 7.4, and 7.9, were added after neutralization to hFOB 1.19 cells. Genome-wide microarray analysis was performed using the Affymetrix GeneChip 7G Scanner. Biometric, cluster and pathway analyses were performed with GeneSpring GX. Biometric analyses demonstrated that 53 genes were differentially regulated ( $p \leq 0.005, \geq 2$-fold increase). Pathway analysis revealed 10 significant pathways of which eight are common pathways regulating bone formation and cancer growth. Eleven genes were selected for quantitative real-time PCR based on the microarray analysis of the lysed platelets prepared in the $\mathrm{pH} 5.4$ experiments. In conclusion, acidic preparations of lysed platelet concentrates release factors essential for cell proliferation and particularly cell metabolism under hypoxic conditions. The genetic response from these factors was dominated by genes associated with the same pathways observed in bone formation and cancer growth. Activation of TGF- $\beta$ in the acidic preparation could be a stimulatory key factor of cell proliferation. These results support the hypothesis that acidification of platelets modifies the stimulatory response of mesenchymal cells in vitro, which is analogous with the observed milieu of a low $\mathrm{pH}$ present in wound and fracture sites, as well as in growing tumors.
\end{abstract}




\section{Introduction}

Platelets are abundant at sites of wound and fracture healing and are exposed to the varying $\mathrm{pH}$ levels as the healing process progress from the initial inflammatory stage to the later reparative stages. The local environment in the initial fracture hematoma is acidic, which later becomes more alkaline as the healing progress [1]. Platelet-rich plasma and platelet derivates contain several potent growth factors and have, therefore, been used for growth stimulation of a variety of mesenchymal cells [2-5]. Platelet preparations have also been used clinically to stimulate bone formation and wound healing [6-8]. Previous in vitro studies on supernatants of lysed platelet preparations in different $\mathrm{pH}$ buffers have demonstrated increased proliferation of mesenchymal cells particularly when the platelets were prepared in low $\mathrm{pH}[9$, 10].

The low $\mathrm{pH}$ of the buffer simulates the situation in a wound and fracture hematoma, and the space under resorbing osteoclasts. A low $\mathrm{pH}$ is also relevant for the environment of a growing tumor, where the $\mathrm{pH}$ of the extracellular matrix surrounding the tumour cells is low [11]. The platelets present at a wound and fracture site will be activated or lysed and exposed to the surrounding acidic milieu, and factors activated/solved in low $\mathrm{pH}$ initiate and support the healing process and common cell proliferation. Platelets contain bone morphogenetic proteins (BMPs) [12] and the amount of BMP-2, BMP-4, BMP-6 and BMP-7 varies between different platelet donors and it has also been demonstrated that the extracted amount of BMP from lysed platelet concentrates is $\mathrm{pH}$-dependent $[13,14]$. BMPs play an important role in recruitment, proliferation, and differentiation of mesenchymal cells [15, 16], and BMPs have proved to be potent pharmacological agents in the adult skeleton and are being used in spine fusion, fracture repair, and oral and faciomaxillary surgery [17].

Microarray analysis offers the opportunity for a global survey of gene expression and elucidation of molecular pathways in osteoblast-like cells stimulated by growth factors. 
Previous studies on gene expression in bone formation and fracture healing have shown activation of several pathways including Wnt, PTHR, BMP and TGFBR, and, moreover, growth factors genes have been up-regulated, particularly in the early phase of fracture healing $[18,19]$.

The objective of this study was to use whole genome microarray gene analysis to identify the genes that are regulated in osteoblast-like cells (hFOB 1.19) when treated with supernatants from lysed platelets prepared in acidic, neutral or alkaline buffers. Our hypothesis is that acidic preparations activates genes and pathways associated with basic cell proliferation, and that neutral preparations will activate genes associated with more osteoblast-like mature cell processes. 


\section{Materials and methods}

\section{Preparation of lysed platelets in buffer}

Platelets, $1.9 \times 10^{12}$ cells/L, were harvested from one healthy platelet donor (male, 36 years of age) who previously had a verified release of significant levels of BMPs in supernatants of lysed platelets in buffer (LPB) [13]. The used LPBs (at pH 5.4, 7.4, and 7.9) had detectable amounts of BMP-2 (range 20-28 ng/L), BMP-4 (366-583 ng/L), BMP-6 (402-641 ng/L), and high levels of platelet-derived growth factor (PDGF) (18940-22007 ng/L), but no detectable BMP-7. The platelet concentrate, free of leukocyte components, was prepared by standardized and certified procedures at the Blood Center at Linköping University Hospital, Sweden, and stored at $-70^{\circ} \mathrm{C}$ prior to use. Platelets were rapidly thawed in a water bath at $37^{\circ} \mathrm{C}$ and $\mathrm{pH}$ was adjusted to 5.4, 7.4, and 7.9 by dilution 1:1 with three different buffers: (1) 0.2 M sodium acetate, $\mathrm{pH}$ 5.0; (2) phosphate-buffered saline (PBS), pH 7.5; and (3) 0.05 M Tris pH 8.0. The LPB preparations were incubated overnight at $37^{\circ} \mathrm{C}$ and subsequently diluted $1: 1$ with $4 \%$ bovine serum albumin in PBS.

\section{Determination of growth factor concentrations}

PDGF (PDGF-AB), BMP-2, BMP-4, BMP-6, and BMP-7, were quantified (prior dilution with $4 \%$ bovine serum albumin) in the supernatant from lysed platelets, by quantitative enzyme-linked immunosorbent assays (ELISA) (PDGF-AB and BMP-2, R\&D Systems, Minneapolis, MN; and BMP-4, BMP-6 and BMP-7, RayBiotech Inc., Norcross, GA). The acidic sample $\mathrm{pH}$ did not change assay recovery because each sample is neutralized (to $\mathrm{pH}$ 6.5) during analysis. The minimum detection limits were $2 \mathrm{ng} / \mathrm{L}$ for PDGF, $10 \mathrm{ng} / \mathrm{L}$ for BMP7, $11 \mathrm{ng} / \mathrm{L}$ for BMP-2, and $15 \mathrm{ng} / \mathrm{L}$ for BMP-4 and BMP-6. 


\section{Cell culture methods}

Human osteoblast-like cells, hFOB 1.19, from the American Type Culture Collection (Manassas, VA, USA) were used throughout the current study. The hFOB 1.19 cells provides a homogeneous and rapidly proliferating model system for studying normal human osteoblast differentiation, osteoblast physiology, and hormonal, growth factor, and other cytokine effects on osteoblast function and differentiation [20]. The hFOB cells were grown in a 1:1 mixture of Ham's F12 medium and Dulbecco's modified Eagle's medium (without phenol red) supplemented with $10 \%$ fetal bovine serum, $2.5 \mathrm{mM} \mathrm{L-glutamine,} 0.3 \mathrm{mg} / \mathrm{mL}$ of neomycin G418 (Sigma Chemical Co., St. Louis, MO, USA) and incubated at $34^{\circ} \mathrm{C}$ with $95 \%$ humidity and $5 \% \mathrm{CO}_{2}$. Cells were plated out in $100 \mathrm{~mm}$ plates at an initial density of $12 \times 10^{4}$ cells $/ \mathrm{mL}$ (that is, approximately $35 \%$ confluence), in a total volume of $10 \mathrm{~mL} /$ plate and medium was changed after $24 \mathrm{~h}$ to serum-free conditions. Medium was removed after an additional incubation of $24 \mathrm{~h}$ and replaced with medium including $18 \%$ of the three different preparations of LPB (i.e., at $\mathrm{pH}$ 5.4, 7.4, and 7.9). The acidic LPB was brought to neutral $\mathrm{pH}$ by adding $2 \mathrm{M} \mathrm{NaOH}$ and all LPBs were sterilized through $0.22 \mathrm{~mm}$ syringe filters (Sartorius AG, Goettingen, Germany). The hFOB cells were grown for $24 \mathrm{~h}$ before isolation of total RNA. Identical culture conditions (including $4 \%$ bovine serum albumin) were used for the hFOB control cells except that the platelet concentrate was replaced by $0.9 \% \mathrm{NaCl}$.

\section{Isolation of total RNA}

RNA was prepared from three controls, two LPB 5.4, two LPB 7.4 and two LPB 7.9 preparations, using Trizol reagent (Invitrogen, Pacely, Scotland) followed by purification on an RNeasy MinElute Total RNA preparation kit (Qiagen, Düsseldorf, Germany), and the concentration of obtained RNA was measured spectrophotometrically. Five $\mu \mathrm{g}$ of total RNA was labeled and amplified according to Affymetrix GeneChip Expression Analysis Technical 
Manual. For quantitative real-time PCR (qPCR) verification of the LPB 5.4 preparation, total RNA was extracted with the RNeasy Protect Mini Kit (Qiagen, Solna, Sweden).

\section{qPCR}

qPCR were performed on a 7500 Fast Real-Time PCR system (Applied Biosystems, Stockholm, Sweden). cDNA was obtained using High Capacity RNA-to-cDNA Kit (Applied Biosystems) and FAM/MGB-labeled probes (Applied Biosystems). All reactions and conditions were according to the manufacturer's instructions. Glyceraldehyde 3-phosphate dehydrogenase was amplified as an internal standard. Data were calculated using the comparative $\mathrm{Ct}$ method which presents the data as a fold-difference in expression levels relative to a calibrator sample [21].

\section{Microarray and statistical analysis}

Labeled cRNA was hybridized to Human Genome U133 Plus 2.0 Chips and scanned using an Affymetrix GeneChip 7G Scanner. Initial analysis and CEL data files were produced using the Affymetrix GeneChip Operating Software (GCOS) ver. 1.4. Gene expression signal-level data were computed with the robust multi-array average method using default settings, $\log$ transformed, and normalized to total intensities with GeneSpring® GX 10.0.1 using a guided workflow step. Signal intensity values were selected between 20.0 and 100 percentile of each chip and for each individual gene. Significant differentially expressed genes were identified using one-way ANOVA. The Benjamini-Hochberg false discovery rate multiple test correction was applied whenever applicable. Significantly differentially expressed genes by $>2.0$-fold change at $p<0.005$ were used for further analysis. Hierarchical cluster analysis was performed to assess correlations among samples for each identified gene set with Euclidean distance and average linkage statistical methods. Pathway analysis, on genes identified after 
$20 \%$ expression filtering and ANOVA $p \leq 0.05$; was carried out to classify genes based on their biological process and molecular function. 


\section{Results}

Fifty-three genes were identified that were significantly differentially expressed using the criteria described in the Material and Methods section (Table I, Figures 1 and 2). Cluster analysis of these 53 genes revealed three clusters that divided them into genes that were: cluster 1, up-regulated with LPB 5.4 (Figure 3); cluster 2, up-regulation of control cells; and cluster 3, down-regulation of control cells. Twenty-one up-regulated genes were observed within cluster 1 and the function for most of these genes is characterized by cell proliferation, cell differentiation, regulation of angiogenesis, tumor genesis and inflammatory processes. The dominating genes within cluster 1 are associated with pathways of cell proliferation, integrins, angiogenesis, and inflammation. Cluster 2 comprised 20 up-regulated genes in the control cells, which were dominated by genes associated with cholesterol/lipid metabolism and steroid synthesis. Cluster 3, with 12 down-regulated genes in the control cells, contained genes associated with cellular functions, regulation of the cytoskeleton, and protein folding.

Treatment with LPB 7.4 and LPB 7.9 caused minor up-regulation of some genes (PPAP2B, HSPC111 and PPIF) which are not associated with common pathways (Table I). The genes SLC46A3 (rank 19), C1orf104 (rank 22), ACTG2 (rank 18) were greatly downregulated in LPB 7.4 and LPB 7.9 (Table I, Figure 3). Some genes belonging to the integrin signaling pathway, i.e., ACTG2 (rank 18), ACTA2 (rank 2), and TNS1 (rank 8), were significantly up-regulated in LPB 5.4 but down-regulated in LPB 7.4 and LPB 7.9 (Table I; Figure 3).

Statistical pathway analysis of the genome-wide microarray results from the LPB treated cell cultures displayed 1617 genes associated with 10 significant pathways, i.e., Alpha6beta4 integrin, androgen receptor, EGFR1, hedgehog, IL2, IL4, NOTCH, TGFBR, TNFalpha/NFkB, and Wnt (Table II). Eight out of these pathways are common with the 10 pathways reported by the Cancer Cell Map [22], which is a collection of human-focused 
cellular pathways implicated in cancer that are linked to visualization and analysis tools selected by the Computational Biology Center at Memorial Sloan-Kettering Cancer Center, New York, NY, USA. The two other, i.e., IL2 and IL4, are involved in inflammatory processes.

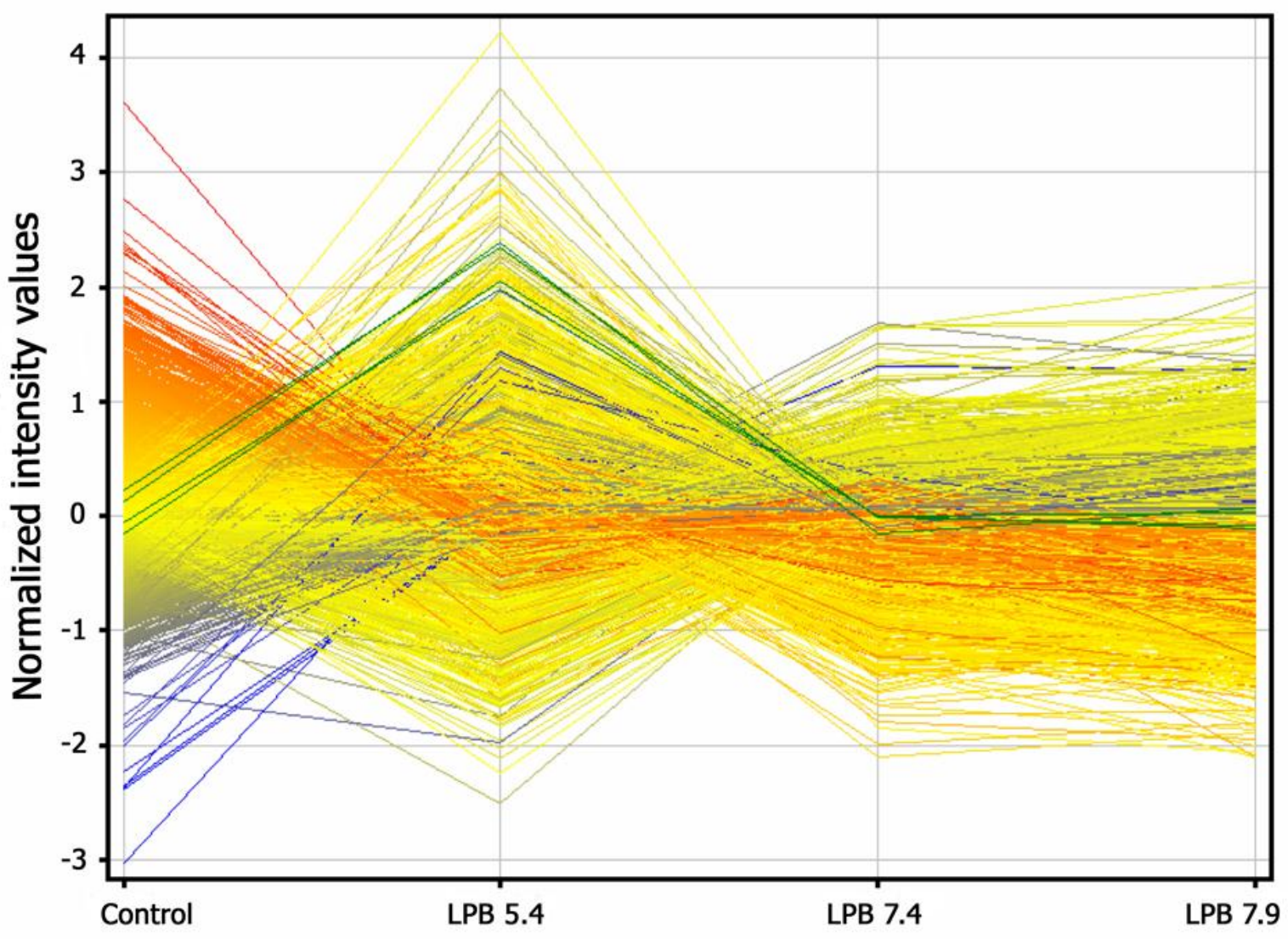

Figure 1. Expression pattern of the total genes analyzed. The four VEGF genes are marked in green out of the total of 54675 genes investigated in the genome-wide microarray analysis. The VEGF genes are markedly up-regulated in LPB 5.4, which was confirmed by qPCR (Tables III and IV).

None of the BMPs was up- or down-regulated and they did not follow the same pattern as TGF- $\beta$ or FGF. However, the BMP-2 receptor gene was up-regulated in LPB 5.4, and down-regulated in LPB 7.4 and LPB 7.9. Vascular endothelial growth factor (VEGF) was upregulated in LPB 5.4 (Figure 1). The hypoxia inducible factor 1 (HIF1A) was up-regulated in 


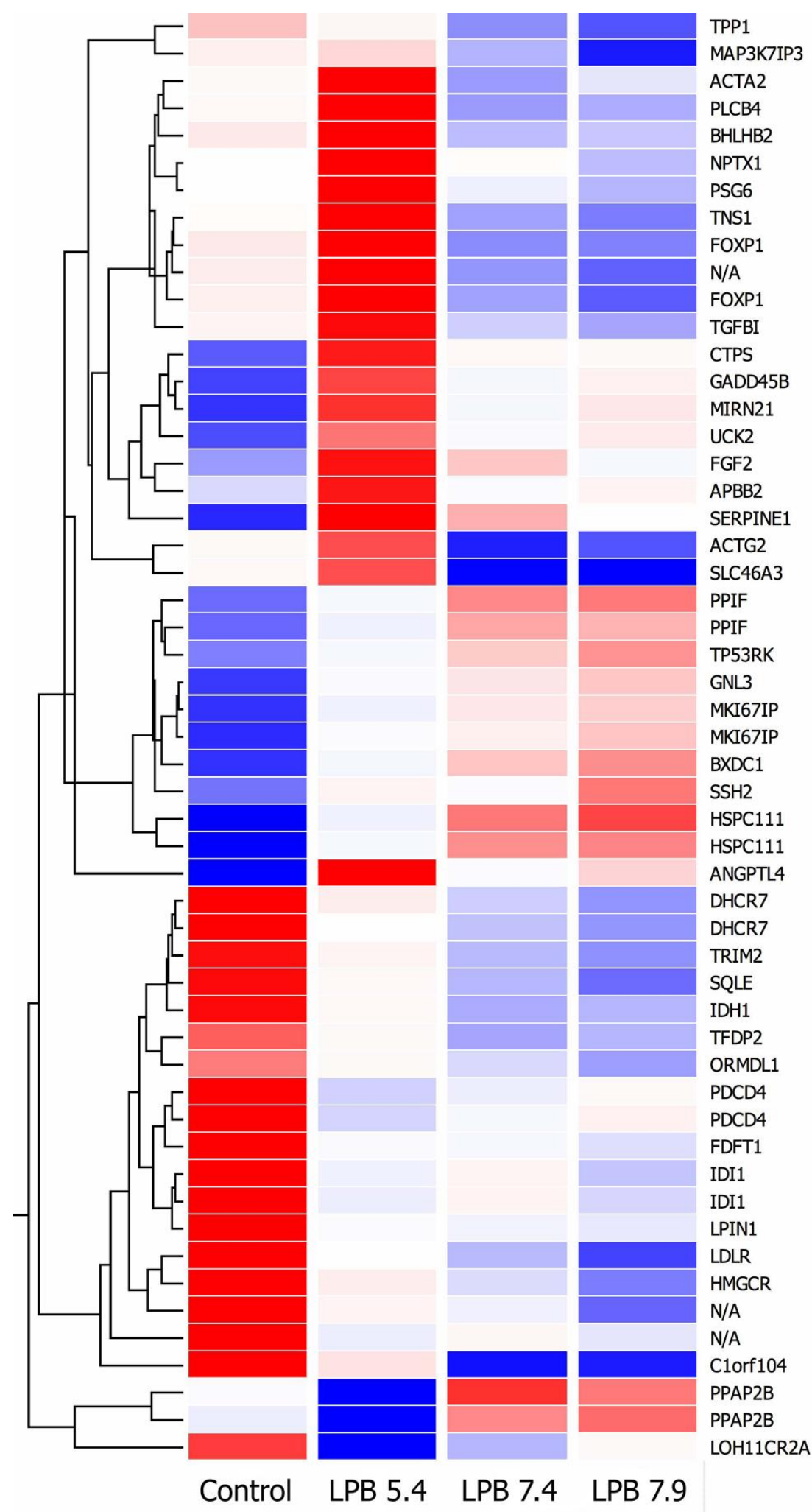

Figure 2. Heatmap. The 53 significantly up- or down-regulated genes (20\% expression, $p \leq$ 0.005, 2-fold increase). Controls, LPB 5.4, LPB 7.4, and LPB 7.9. Red indicates up-regulated genes and blue down-regulated. 


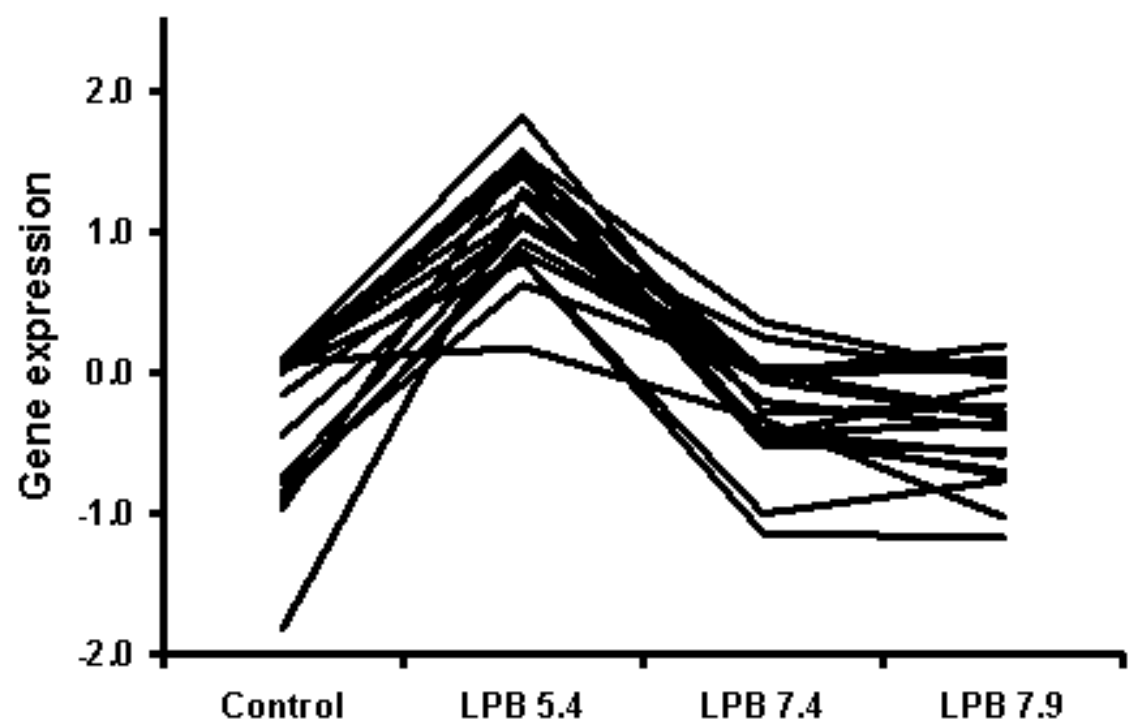

$\begin{array}{lrrrrc}\text { Gene symb ol } & \text { Control } & \text { LPB 5.4 } & \text { LPB 7.4 } & \text { LPB 7.9 } & \text { Rank } \\ \text { BHLHB2 } & 0.097 & 1.810 & -0.287 & -0.237 & 1 \\ \text { ACTA2 } & 0.021 & 1.568 & -0.444 & -0.105 & 2 \\ \text { SERPINE1 } & -0.962 & 1.540 & 0.356 & 0.000 & 3 \\ \text { PSG6 } & 0.006 & 1.512 & -0.057 & -0.318 & 4 \\ \text { NPTX1 } & 0.008 & 1.502 & 0.010 & -0.288 & 5 \\ & 0.079 & 1.470 & -0.464 & -0.702 & 6 \\ \text { PLCB4 } & 0.033 & 1.436 & -0.438 & -0.358 & 7 \\ \text { TNS1 } & 0.012 & 1.421 & -0.410 & -0.588 & 8 \\ \text { FOXP1 } & 0.098 & 1.401 & -0.513 & -0.555 & 9 \\ \text { ANGPTL4 } & -1.818 & 1.292 & -0.006 & 0.191 & 10 \\ \text { FOXP1 } & 0.072 & 1.248 & -0.416 & -0.734 & 11 \\ \text { TGFB 1 } & 0.047 & 1.107 & -0.207 & -0.396 & 12 \\ \text { FGF2 } & -0.441 & 1.077 & 0.245 & -0.027 & 13 \\ \text { APBB2 } & -0.158 & 1.053 & -0.007 & 0.049 & 14 \\ \text { CTPS } & -0.740 & 1.034 & 0.028 & 0.025 & 15 \\ \text { MIRN21 } & -0.906 & 0.930 & -0.030 & 0.100 & 16 \\ \text { GADD45B } & -0.848 & 0.847 & -0.035 & 0.055 & 17 \\ \text { ACTG2 } & 0.019 & 0.800 & -1.001 & -0.767 & 18 \\ \text { SLC46A3 } & 0.029 & 0.789 & -1.142 & -1.172 & 19 \\ \text { UCK2 } & -0.790 & 0.623 & -0.014 & 0.084 & 20 \\ \text { MAP3K7IP3 } & 0.069 & 0.174 & -0.334 & -1.025 & 21\end{array}$

Figure 3. Cluster analysis. Genes up-regulated in osteoblast-like cells treated with LPB 5.4 (cluster 1). 
LPB 5.4 and carbonic anhydrase XII (CA12) was also up-regulated in LPB 5.4 as demonstrated by qPCR (Tables III and IV).

Eleven genes were selected for qPCR analysis to verify the microarray results from the LPB 5.4 experiments, i.e., 7 up-regulated genes (ACTA2, ACTG2, TNS1, FGF2, TGFB1, CTPS and ANGPLT4) and 1 down-regulated gene (LOH11CR2A), in addition to 3 genes important for hypoxic conditions (CA12, HIF1A and VEGFA). To verify the microarray data, total RNA was extracted from cells treated with LPB 5.4, and the ensuing qPCR analysis confirmed the results of 10 of the 11 genes tested. ACTA2 was down-regulated according to the qPCR but up-regulated in the microarray analysis (Table III). 


\section{Discussion}

Microarray genome-wide analysis of human osteoblast-like cells, hFOB 1.19, stimulated with lysed platelet concentrates revealed several genes that are involved in molecular signaling pathways responsible for the mechanisms controlling fracture healing. Differentiation of osteoblasts is mediated by Runx 2 activation. Six of the significant pathways in this study are common with the nine characterized pathways involved in Runx2-mediated osteoblast differentiation: TGF- $\beta$, Wnt, FGF, EGFR1, TNFalpha/NFkB, and NOTCH. The three other pathways are BMP, PTHR and IGFR [18]. None of the known BMPs was up-regulated, but BMPR2 was up-regulated in LPB 5.4 and down-regulated in LPB 7.4 and LPB 7.9, as well as in the control cell cultures. This finding may indicate that the receptor gene is up-regulated before the BMP gene itself. The presence of BMPs in the investigated LPBs was similar in LPB 5.4, LPB 7.4 and LPB 7.9, and can, therefore, not explain the found differences between the LPB groups and, moreover, the PDGF concentration was high in all three LPB preparations.

Previous in vitro studies have demonstrated increased proliferation of fibroblasts [9] and osteoblast-like hFOB 1.19 cells [10] when these cells were stimulated with acidic LPB preparations compared with platelets prepared in neutral $\mathrm{pH}$. In this study, a significant difference was found regarding gene activation in osteoblast-like cells after stimulation with LPB 5.4. Grainger et al. [23] showed that latent TGF- $\beta$ comprised as much as $95 \%$ of the total TGF- $\beta$ in whole platelets. Latent TGF- $\beta$ can be activated in low $\mathrm{pH}$ in vitro and may explain the stimulatory differences between the different platelet preparations used in this study. Hypothetically, a factor in lysed platelet preparations is activated by the low $\mathrm{pH}$ which results in an up-regulation of genes with similar regulatory mechanisms as the HIF1A transcription factor. The activation of this factor could result in extensive changes in gene expression so that cells will adapt to the low $\mathrm{pH}[11]$. 
The up-regulated genes in cluster 1 (i.e., the genes up-regulated in the cultures stimulated with LPB 5.4) were represented in the significant pathways, while the significant genes of LPB 7.4 and LPB 7.9 were not. Thus, the stimuli from the LPB 5.4 preparations induced activation of several genes and pathways responsible for cell proliferation, such as regulation of angiogenesis, inflammatory processes and tumor genesis. The VEGFA, HIF1A, ANGPTL4 and CA12 genes (all associated with hypoxia) were up-regulated after stimulation with LPB 5.4 and followed the same pattern as the genes associated with cluster 1 .

Our results indicate that factors in the acidic LPB start processes in the cell cultures that involve increased proliferation via 10 significant pathways, of which eight are common with the cancer cell proliferating pathways according to the Cancer Cell Map [22]. The environment of tumors, the initial stage of wound and fracture sites and the sub osteoclastic space are acidic and hypoxic, the content of lysed platelets in these sites would be exposed to the same conditions as the lysed platelets of the LPB 5.4. The factors released from LPB 5.4 may thus be similar to those released in fracture and wound hematoma and in acidic/hypoxic tumors and in the subosteoclastic space. Acidic conditions are relevant to wound/fracture sites but also to the extracellular site of tumors and the tissue of cancer tumors [24, 25]. The content of activated/lysed platelets in the low $\mathrm{pH}$ of the tissue surrounding growing tumors may contribute to the proliferation of the tumor cells and the tumor it self.

The microRNA MIRN21, an important oncogene with an anti-apoptotic role in different cancer growths [26], was up-regulated in LPB 5.4 compared with LPB 7.4 and downregulated in controls (Figure 3). MicroRNAs are small endogenously expressed non-coding RNA molecules regulating gene expression post-transcriptionally. Each microRNA sequence regulates the expression of multiple mRNA sequences, and one mRNA can be regulated by multiple microRNA sequences [27]. Many of these microRNAs modulate major proliferation pathways that have relevant implications not only in physiological or developmental 
processes but also in tumour progression or cancer therapy [28]. Asangani et al. [29] demonstrated that MRNA21 negatively regulates the tumor suppressor gene PDCD4 resulting in increased tumor activity. Lu et al. [30] also found that MRNA21 function as an oncogene by a mechanism that involves translational repression of the tumor suppressor PDCD4. LPB 5.4 resulted in up-regulation of MIRN21 and weakly down-regulated PDCD4 in contrast to controls where MIRN21 was down-regulated and PDCD4 was up-regulated. This indicates that platelets in acidic conditions may release factors that down-regulate tumor suppressor genes which facilitate tumor growth.

Concerning the comparison between LPB 5.4 and LPB 7.4/LPB 7.9, there were a surprisingly low number of genes up-regulated in LPB 7.4 and hardly any significant differences between LPB 7.4 and LPB 7.9. Interestingly, ACTG2, ACTA2 and TNS1 (Table I), belonging to the integrin signaling pathway, were significantly up-regulated in LPB 5.4 but down-regulated in LPB 7.4 and LPB 7.9. The integrin signaling pathway contributes to basic proliferation of mesenchymal cells which supports our general hypothesis that acidic LPB preparations contribute to basic proliferation of mesenchymal cells. Concerning the controls, there was a typical difference compared with the LPB treated cells. Genes up-regulated in the starving control cells were dominated by lipid/cholesterol metabolism and steroid synthesis (Table I). The significant up-regulation of steroids in the starving osteoblast-like cells may indicate the importance of steroids in the bone forming process or it is a general reaction to cells deprived of exogen steroids.

Comparisons with in vivo studies on fracture healing with in vitro model are difficult. However, Rundle et al. [19] found early up-regulation of TGF- $\beta$ and VEGF, consistent with previous fracture studies; which was an important result of our in vitro model in addition to the up-regulation of integrins. The traditional markers of osteoblastic differentiation (i.e., collagen type I, alkaline phosphatase and osteocalcin) were not up-regulated. The signaling 
PTH and BMP pathways were not up-regulated, which could indicate that 24 hours is too short culture period. Or the cultured cells need other stimuli to up-regulate genes necessary for later osteoblastic differentiation.

In vivo, acidic $\mathrm{pH}$ is a consequence of low tissue $\mathrm{pO}_{2}$. In a wound or fracture site, where the circulation is damaged, the $\mathrm{pO}_{2}$ decreases and the wound/fracture hematoma becomes acidic. Platelets present in these fracture sites will thus be exposed to the lower $\mathrm{pH}$, which will result in the release of factors which will improve cell metabolism/proliferation in acidic/hypoxic milieu. The factors released from platelets (under these conditions) will probably contain the same factors as platelets prepared in acidic buffer. The same condition is also present at the vicinity of active osteoclasts.

In conclusion, we identified 53 genes (after stringent filtering prior to statistical analyses) in osteoblast-like hFOB 1.19 cells that changed their gene expression significantly after treatment with supernatants from lysed platelet preparations. Twenty-one of these genes were significantly up-regulated in the osteoblast-like cells after treatment with the acidic preparation of LPB at $\mathrm{pH}$ 5.4. The genetic response was dominated by genes associated with the same pathways observed in bone formation and cancer growth. QPCR analysis verified the down-regulation of the tumor suppressor gene (LOH11CR2A) and the up-regulation of the ANGPTL4, VEGF, CA12, and HIF1A genes. These genes are involved in vascularization and metabolism under hypoxic conditions; however, the used conditions for cell culture were not hypoxic during the experimental procedure. It is, therefore, likely that the observed upregulation of these hypoxic genes originates from factors released from the platelets treated in acidic buffer, e.g., activated TGF- $\beta$.

Further investigations are necessary to specifically characterize the factors in the acidified lysed platelets responsible for the demonstrated gene response and the increased proliferation. Platelet-rich plasma, and other derivates of platelets, are used clinically for 
stimulation of bone formation and wound healing. Acidification of platelet preparations may provide a more potent efficacy; however, the demonstrated activation of significant pathways common with the pathways of the Cancer Cell Map merit further consideration.

\section{Acknowledgements}

This study was supported by grants from the Swedish Society of Medicine and the County Council of Östergötland, Sweden. We thank Marie Trinks for assistance and preparation of the platelet concentrates.

\section{Declaration of interest}

The authors report no declarations of interest. 


\section{References}

1. Hollinger J, Wong MEK. The integrated processes of hard tissue regeneration with special emphasis on fracture healing. Oral Surg Oral Med Oral Pathol Oral Radiol Endod 1996;82:594-606.

2. Dallari D, Fini M, Stagni C, Torricelli P, Aldini NN, Giavaresi G, Cenni E, Baldini N, Cenacchi A, Bassi A, Giardino R, Fornasari PM, Giunti A. In vivo study on the healing of bone defects treated with bone marrow stromal cells, platelet-rich plasma, and freezedried bone allografts, alone and in combination. J Orthop Res 2006;24:877-888.

3. Gruber R, Karreth F, Kandler B, Fuerst G, Rot A, Fischer MB, Watzek G. Plateletreleased supernatants increase migration and proliferation, and decrease osteogenic differentiation of bone marrow-derived mesenchymal progenitor cells under in vitro conditions. Platelets 2004;15:29-35.

4. Slater M, Patava J, Kingham K, Mason RS. Involvement of platelets in stimulating osteogenic activity. J Orthop Res 1995;13:655-663.

5. Vogel JP, Szalay K, Geiger F, Kramer M, Richter W, Kasten P. Platelet-rich plasma improves expansion of human mesenchymal stem cells and retains differentiation capacity and in vivo bone formation in calcium phosphate ceramics. Platelets 2006;17:462-469.

6. Alsousou J, Thompson M, Hulley P, Noble A, Willett K. The biology of platelet-rich plasma and its application in trauma and orthopaedic surgery: a review of the literature. J Bone Joint Surg Br 2009;91:987-996.

7. Marx RE, Carlson ER, Eichstaedt RM, Schimmele SR, Strauss JE, Georgeff KR. Platelet-rich plasma. Growth factor enhancement for bone grafts. Oral Surg Oral Med Oral Pathol Oral Radiol Endod 1998;85:638-646. 
8. Steed DL, Goslen JB, Holloway GA, Malone JM, Bunt TJ, Webster MW. Randomized prospective double-blind trial in healing chronic diabetic foot ulcers. CT-102 activated platelet supernatant, topical versus placebo. Diabetes Care 1992;15:1598-1604.

9. Liu Y, Kalén A, Risto O, Wahlström O. Fibroblast proliferation due to exposure to a platelet concentrate in vitro is pH dependent. Wound Repair Regen 2002;10:336-340.

10. Wahlström O, Linder C, Kalén A, Magnusson P. Variation of $\mathrm{pH}$ in lysed platelet concentrates influence proliferation and alkaline phosphatase activity in human osteoblast-like cells. Platelets 2007;18:113-118.

11. Dayan F, Mazure NM, Brahimi-Horn MC, Pouysségur J. A Dialogue between the Hypoxia-Inducible Factor and the Tumor Microenvironment. Cancer Microenviron 2008;1:53-68.

12. Sipe JB, Zhang J, Waits C, Skikne B, Garimella R, Anderson HC. Localization of bone morphogenetic proteins (BMPs)-2, -4 , and -6 within megakaryocytes and platelets. Bone 2004;35:1316-1322.

13. Kalén A, Wahlström O, Halling Linder C, Magnusson P. The content of bone morphogenetic proteins in platelets varies greatly between different platelet donors. Biochem Biophys Res Commun 2008;375:261-264.

14. Wahlström O, Linder C, Kalén A, Magnusson P. Acidic preparations of platelet concentrates release bone morphogenetic protein-2. Acta Orthop 2008;79:433-437.

15. Devlin RD, Du Z, Pereira RC, Kimble RB, Economides AN, Jorgetti V, Canalis E. Skeletal overexpression of noggin results in osteopenia and reduced bone formation. Endocrinology 2003;144:1972-1978.

16. Bandyopadhyay A, Tsuji K, Cox K, Harfe BD, Rosen V, Tabin CJ. Genetic analysis of the roles of BMP2, BMP4, and BMP7 in limb patterning and skeletogenesis. PLoS Genet 2006;2:2116-2130. 
17. Khosla S, Westendorf JJ, Oursler MJ. Building bone to reverse osteoporosis and repair fractures. J Clin Invest 2008;118:421-428.

18. Krause C, de Gorter DJJ, Karperien M, ten Dijke P. Signal transduction cascades controlling osteoblast differentiation. In: Rosen CJ, editor. Primer on the metabolic bone diseases and disorders of mineral metabolism. 7:th ed. Washington, D.C., USA: American Society for Bone and Mineral Research; 2008. p. 10-16.

19. Rundle CH, Wang H, Yu H, Chadwick RB, Davis EI, Wergedal JE, Lau K-HW, Mohan S, Ryaby JT, Baylink DJ. Microarray analysis of gene expression during the inflammation and endochondral bone formation stages of rat femur fracture repair. Bone 2006;38:521-529.

20. Harris SA, Enger RJ, Riggs BL, Spelsberg TC. Development and characterization of a conditionally immortalized human fetal osteoblastic cell line. J Bone Miner Res 1995;10:178-186.

21. Leutenegger CM, Mislin CN, Sigrist B, Ehrengruber MU, Hofmann-Lehmann R, Lutz H. Quantitative real-time PCR for the measurement of feline cytokine mRNA. Vet Immunol Immunopathol 1999;71:291-305.

22. http://cancer.cellmap.org/cellmap The Computational Biology Center at Memorial Sloan-Kettering Cancer Center, New York, NY, USA.

23. Grainger DJ, Wakefield L, Bethell HW, Farndale RW, Metcalfe JC. Release and activation of platelet latent TGF-beta in blood clots during dissolution with plasmin. Nature Med 1995;1:932-937.

24. Bertout JA, Patel SA, Simon MC. The impact of $\mathrm{O}_{2}$ availability on human cancer. Nat Rev Cancer 2008;8:967-975.

25. Franovic A, Holterman CE, Payette J, Lee S. Human cancers converge at the HIF2alpha oncogenic axis. Proc Natl Acad Sci USA 2009;106:21306-21311. 
26. Papagiannakopoulos T, Shapiro A, Kosik KS. MicroRNA-21 targets a network of key tumor-suppressive pathways in glioblastoma cells. Cancer Res 2008;68:8164-8172.

27. Bartel DP. MicroRNAs: target recognition and regulatory functions. Cell 2009;136:215233.

28. Bueno MJ, de Castro IP, Malumbres M. Control of cell proliferation pathways by microRNAs. Cell Cycle 2008;7:3143-3148.

29. Asangani IA, Rasheed SA, Nikolova DA, Leupold JH, Colburn NH, Post S, Allgayer H. MicroRNA-21 (miR-21) post-transcriptionally downregulates tumor suppressor Pdcd4 and stimulates invasion, intravasation and metastasis in colorectal cancer. Oncogene $2008 ; 27: 2128-2136$.

30. Lu Z, Liu M, Stribinskis V, Klinge CM, Ramos KS, Colburn NH, Li Y. MicroRNA-21 promotes cell transformation by targeting the programmed cell death 4 gene. Oncogene 2008;27:4373-4379. 
Table I. Significantly expressed genes $(n=53)$ ranked based on their expression in LBP 5.4.

Filtration: expression $20 \%, p \leq 0.005, \geq 2$-fold variation

\section{Rank Probe set ID Gene symbol Gene title}

\begin{tabular}{|c|c|c|c|}
\hline 1 & $201170 \mathrm{~s}$ at & BHLHB2 & Basic helix-loop-helix domain containing, classB2 \\
\hline 2 & 200974 at & ACTA2 & Actin alpha 2 \\
\hline 3 & $202628 \mathrm{~s}$ at & SERPINE1 & Serpin peptidase inhibitor, clade E, member 1 \\
\hline 4 & $208106 \mathrm{x}$ at & PSG6 & Pregnant specific beta-1-glycoprotein 6 \\
\hline 5 & 204684 at & NPTX1 & Neuronal pentraxin 1 \\
\hline 6 & 229844 at & & Transcribed.. \\
\hline 7 & 203895 at & PLCB4 & Phospholipase C, beta 4 \\
\hline 8 & 221747 at & TNS1 & Tensin 1 \\
\hline 9 & 224838 at & FOXP1 & Forkhead box P1 \\
\hline 10 & $221009 \mathrm{~s}$ at & ANGPTL4 & Angiopoietin-like protein 4 \\
\hline 11 & 224837 at & FOXP1 & Forkhead box P1 \\
\hline 12 & 201506 at & TGFB1 & Transforming growth factor beta 1 \\
\hline 13 & $204421 \mathrm{~s}$ at & FGF2 & Fibroblast growth factor 2 \\
\hline 14 & 40148 at & $\mathrm{APBB} 2$ & $\begin{array}{l}\text { Amyloid beta precursor protein-binding, family B, } \\
\text { member } 2\end{array}$ \\
\hline 15 & 202613 at & CTPS & CTP synthase \\
\hline 16 & 224917 at & MIRN21 & Micro RNA 21 \\
\hline 17 & $209304 \mathrm{x}$ at & GADD45B & Growth arrest and DNA-damage inducible, beta \\
\hline 18 & 202274 at & ACTG2 & Actin gamma 2 \\
\hline 19 & 214719 at & SLC46A3 & Solute carrier family 46, member 3 \\
\hline 20 & $209825 \mathrm{~s}$ at & $\mathrm{UCK} 2$ & Uridine-cytidine kinase 2 \\
\hline 21 & $1552928 \mathrm{~s}$ at & MAP3K7IP3 & $\begin{array}{l}\text { Mitogen-activated protein kinase kinase kinase } 7 \\
\text { interacting protein } 3\end{array}$ \\
\hline 22 & 230256 at & C1orf104 & Chromosome 1 open reading frame 104 \\
\hline 23 & $202539 \mathrm{~s}$ at & HMGCR & $\begin{array}{l}\text { 3-hydroxy-3-methylglutaryl-Coenzyme A } \\
\text { reductase }\end{array}$ \\
\hline 24 & $201790 \mathrm{~s}$ at & DHCR7 & 7-dehydrocholesterol reductase \\
\hline 25 & $215945 \mathrm{~s}$ at & TRIM2 & Tripartite motif-containing 2 \\
\hline 26 & $1554114 \mathrm{~s}$ at & $\mathrm{SSH} 2$ & Slingshot homolog 2 \\
\hline
\end{tabular}




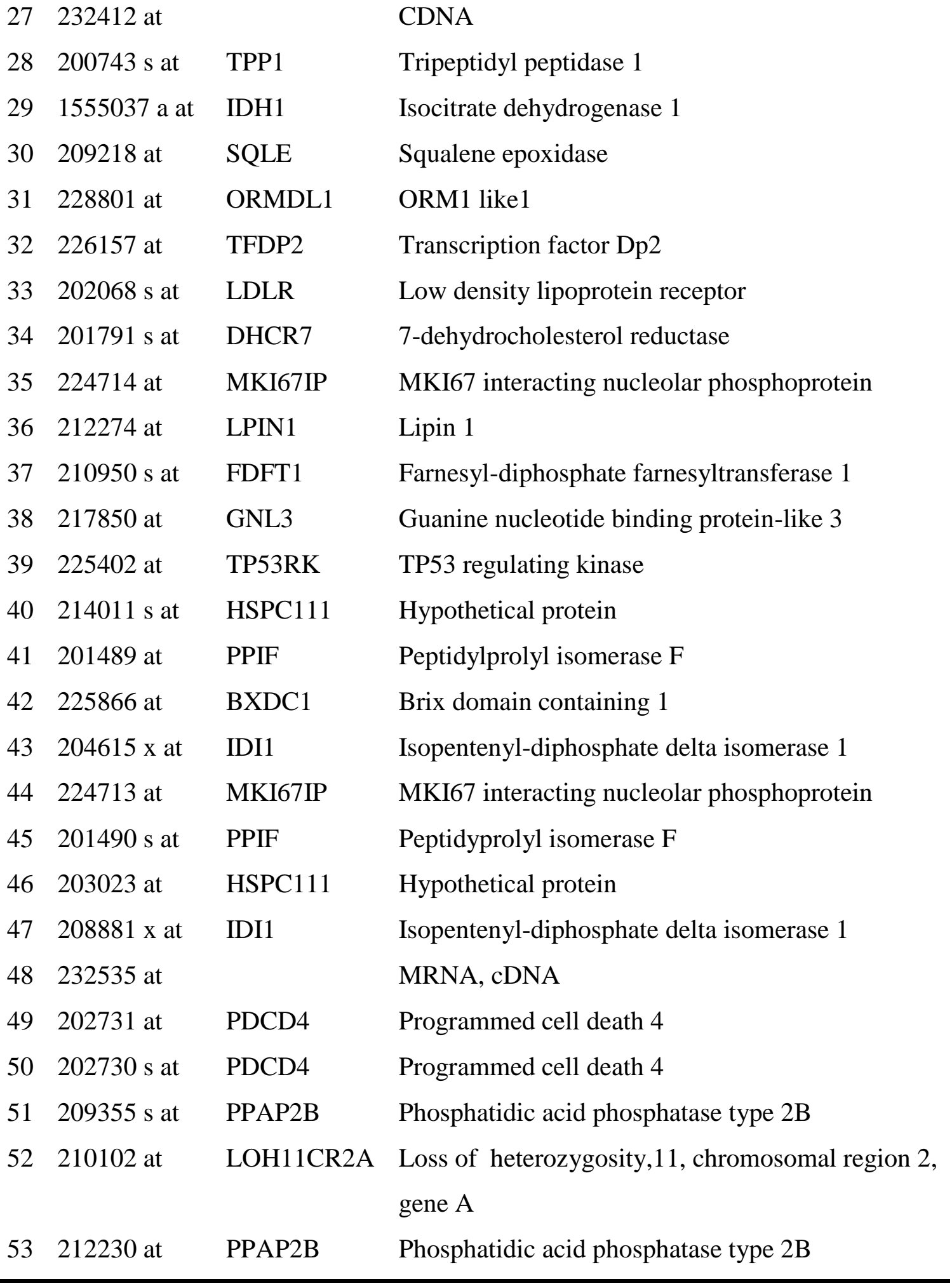


Table II. Statistical pathway analysis of the genome-wide microarray results with $20 \%$ expression filtering and ANOVA, $p \leq 0.05$, displayed 1617 genes associated with 10 significant pathways

\begin{tabular}{ll}
\hline Pathway & p value \\
\hline TGFBR & 0.00000053 \\
EGFR1 & 0.0000047 \\
NOTCH & 0.000016 \\
TNFalpha/NFkB & 0.000025 \\
Androgen receptor & 0.000087 \\
Wnt & 0.0022 \\
Hedgehog & 0.014 \\
IL2 & 0.014 \\
Alpha6beta4 integrin & 0.018 \\
IL4 & 0.047 \\
\hline
\end{tabular}

Eight of these pathways were common with the 10 pathways reported by the Cancer Cell Map [22]. The other, IL2 and IL4, are involved in inflammatory processes. 
Table III. Ten up-regulated genes and 1 down-regulated gene from hFOB 1.19 cells treated with LPB 5.4 as demonstrated with microarray analysis and validated with qPCR. The significant up-regulation of ACTA2 by microarray was not confirmed by qPCR.

\begin{tabular}{lll}
\hline Gene symbol & Microarray & qPCR \\
& & Ratio LPB 5.4/control \\
\hline LOH11CR2A & -1.592 & 0.4 \\
ACTA2 & 1.568 & 0.4 \\
ACTG2 & 0.800 & 1.1 \\
TNS1 & 1.421 & 6.6 \\
FGF2 & 1.077 & 2.0 \\
TGFB1 & 1.107 & 1.6 \\
CTPS & 1.034 & 1.7 \\
ANGPTL4 & 1.292 & 19.3 \\
VEGFA & $2.190 *$ & 3.0 \\
HIF1A & $0.535 *$ & 1.9 \\
CA12 & $0.442 *$ & 3.1 \\
\hline
\end{tabular}

* = Not among the 53 significantly expressed genes by microarray analysis (Table I). 
Table IV. Normalized intensity values of VEGFA, HIF1A, CA12 and BMPR2 from the microarray analysis. These genes followed the same pattern as the genes of cluster 1

\begin{tabular}{lllll}
\hline Gene symbol & Control & LPB 5.4 & LPB 7.4 & LPB 7.9 \\
\hline VEGFA & 0.038 & 2.190 & -0.081 & -0.027 \\
HIF1A & 0.018 & 0.535 & 0.016 & -0.009 \\
CA12 & 0.029 & 0.442 & -0.082 & -0.240 \\
BMPR2 & 0.142 & 0.450 & -0.502 & -0.968 \\
\hline
\end{tabular}

